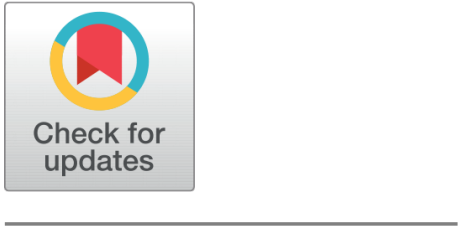

OPEN ACCESS

Received: 20-05-2020

Accepted: $30-07-2020$

Published: 19-08-2020

Editor: Dr. Natarajan Gajendran

Citation: Rajeev Kumar C, Sanjay Kumar M (2020) An approach of multistage distribution system network expansion planning considering investment, operational cost and reliability of system. Indian Journal of Science and Technology 13(30): 3025-3040. https://doi.org/ 10.17485/IJST/v13i30.678

*Corresponding author.

rajeevchauhan@ggits.org

Funding: None

Competing Interests: None

Copyright: (c) 2020 Rajeev Kumar \& Sanjay Kumar. This is an open access article distributed under the terms of the Creative Commons Attribution License, which permits unrestricted use, distribution, and reproduction in any medium, provided the original author and source are credited.

Published By Indian Society for Education and Environment (iSee)

ISSN

Print: 0974-6846

Electronic: 0974-5645

\section{An approach of multistage distribution system network expansion planning considering investment, operational cost and reliability of system}

\author{
Chauhan Rajeev Kumar ${ }^{1,2 *}$, Maurya Sanjay Kumar \\ 1 Research Scholar, Electrical Engineering Department, G. L. A. Mathura, University, U. P, \\ 281406, India \\ 2 Assistant Professor, Electrical Engineering Department, GGITS, Jabalpur, 482003, M.P, India \\ 3 Associate Professor, Electrical Engineering Department, G. L. A. Mathura, University, U. P, \\ 281406, India
}

\section{Abstract}

Objectives: To solve the Multistage Distribution System Planning (MSDSP) problem by a solution strategy based on investment cost, operational cost and reliability of electric power distribution system network. Method: A distinctive multi- objective function model has been developed to compute the expansion period wise cost of investment, operational cost (cost of energy losses in the distribution network) and system reliability is evaluated in terms of Non-Supplied Energy Cost (NSEC) under contingency conditions. Findings: The computed result presents the cost of investment of new equipment, operational cost and NSEC for each period of network expansion along with overall cost of investment in all periods of network expansion. Results obtained also demonstrate the corresponding bus nodes voltages in per unit (pu) for each period of network expansion to satisfy the technical constraints of the voltage profiles. Novelty: A distinctive multi-objective function model is developed to solve MSDSP problem with planning \& operational constraints and results obtained encourages the prospects related to the technical, economical and system reliability issues of electric power distribution system network.

Keywords: Multistage distribution system planning (MSDSP); investment cost; operational cost; distribution system reliability; non-supplied energy cost (NSEC); load flow studies

\section{Introduction}

Deregulation of the power sector has resulted in significant restructuring of the power system, especially in power distribution system network because its complexity, the weakest and highly unreliable element of the electric power system. As power distribution system network directly links the end users, so this motivates the researchers and planners to design lucrative, reliable, and active power distribution system network, which are the major requirements of modern integrated power 
system of today's world. As per the literature, there are two types of approaches that are in practice for electric power distribution system network expansion planning: Single Stage -Static Planning and Multistage -Dynamics Planning ${ }^{(1)}$. In MSDSP the expansion of the distribution system should be in successive plans over several stages/periods, representing the natural course of progression in developments. The optimal solution of MSDSP problem can be a difficult job because of its complexity due to presence of number of variables, uncertainties and interdependency of the planning stages. Due to the completely dynamic nature of the problem and inclusion of binary decision variables which decides when and how much investment cost is to be put in the investment of new equipment's for the multistage expansion of distribution network ${ }^{(2)}$. So to deal with MSDSP problem, a novel or distinctive multi-objective model should be developed with the consideration of three general attributes. These three general attributes are investment cost, operational cost (cost of technical losses or $\mathrm{I}^{2} \mathrm{R}$ losses) ${ }^{(3)}$ and system reliability with growing and changing load demand in each stage at new load points and existing load points ${ }^{(4)}$. In case of MSDSP the distribution network should be expanded in such a manner that the total investment cost, operational cost and NSEC should be minimum up to the last stage of network expansion by satisfying the various technical planning constraints.

Solutions with various objectives and detailed analysis of MSDSP problem are presented and have been solved by the researchers in the past; a different approach is used to solve the MSDSP problem considering the future uncertainties for the selection of best strategy with new balanced genetic algorithms is conceptualized that improves the solution search by trading off poor solutions ${ }^{(5)}$. In ${ }^{(6,7)}$, a different model is used for MSDSP problem including distributed generation, the objective function deals with the installation cost and utilization of the distributed generation and load shedding. In $^{(8)}$, a MSDSP problem of active distribution system is presented using a methodology based on artificial bee colony algorithm. The results and quality of solution has matched and improved over other optimization algorithms. But in this study, system reliability issues are not considered in the formulated objectives. A new model based MSDSP problem is considered with a modified cost biased encoding and decoding techniques and possibilities of variation of loads and uncertainties in loads are solved using particle swarm optimization ${ }^{(9,10)}$. In ${ }^{(11)}$, a multi objective MSDSP problem taken in to the account and an objective function is formulated with cost (investment and operational) and reliability which is evaluated using NSEC but in the results some investments are ignored and some other's investment decisions are delayed for providing the lower cost of expansion. For optimal expansion of multistage distribution network a newly developed competitive algorithm is used to construct a radial configuration of the distribution network ${ }^{(12)}$. A multi-objective design of advanced power distribution network is presented and tested for 100 bus system in ${ }^{(13-15)}$, which includes technical and economical goals with overall system reliability. The presented results demonstrate better performance and may be helpful for obtaining a typical solution of problem. It is noticed in this work the evaluation of system reliability is not handled properly under contingency conditions. A multiple time frame work is presented in ${ }^{(16)}$, for reliability computation based MSDSP problem and solution validates that integration of DGs in distribution expansion planning can curtail the investment and operational cost. A new multi-stage mathematical model of an integrated distribution system planning is addressed and it is suggested that this mathematical model may be considered as a major crossover towards MSDSP problem which also supports the large scale integration of distributed energy sources in the smart $\operatorname{grid}^{(17)}$. An approach for MSDSP with distribution automation system is presented to help the distribution utilities companies for long term time frame planning to enable their distribution network with automation technologies ${ }^{(18,19)}$, this work has still not evaluated distribution system reliability indices under the applications of automation technologies. In last recent years a profit and incentive based multistage expansion planning models are proposed in ${ }^{(20,21)}$, for mutual benefits of customers and distribution utilities, even global implementation of such planning models needs advanced metering infrastructures and integration of distributed generation sources with technical, economical and system reliability based analysis for MSDSP problem. Recent works focus on MSDSP problem of radial distribution system along with distributed generation sources with energy storage devices to obtain more practical solutions ${ }^{(22)}$.

Conventional approaches for the solutions of MSDSP problem are in use like installation of oversized conductors at initial stage of the expansion of dynamic planning, reconductoring of the initial stage network with growing demand of loads in the later stages. Even all developed models need testing for real MSDSP problem to overcome the issues related to technical, economical and system reliability either in terms of reliability indices and/or evaluation of NSEC under contingency conditions. So in future MSDSP problem may be dealt in more practical way in real time frame ${ }^{(23)}$.

A distinctive multi-objective mathematical model is developed by considering investment cost, operational cost and reliability of the system in this study and non-conventional approaches are used to find out the real solutions for the MSDSP problem. A novel radial load flow study (backward and forward sweep) is used to compute the investment and operational cost throughout the expansion of distribution network. Solutions like optimal routing of feeders, reconfiguration and reconductoring of feeders with the growing load demand are considered to find out the optimal solution of problem. Cost of investment is evaluated for the installation of new feeders lines for new load points, capacity expansion of existing substations and construction of new substations at optimal locations for each expansion period. In proposed multi-objective mathematical 
model load levels, corresponding load factors, load loss factors, load levels duration and variable energy prices are considered for the computation of operational cost, earlier this approach was ignored in MSDSP problem formulation. In this study reliability of the dynamic distribution network system is correctly quantified in each stage of expansion by considering the NSEC function, rather than evaluating the classical reliability indices values like SAIFI, SAIDI, and CAIDI ${ }^{(24)}$. Far end voltages constraints are appropriately investigated at each bus nodes in every stage/period of planning to satisfy the power quality issues.

The developed mathematical model explicitly follows the constraints of radiality, voltage magnitude constraints, current capacities of the feeders and power flow capacities of the existing and newly constructed substations. The branch currents and bus nodes voltages are determined by the radial backward and forward sweep based load flow studies in each stage of expansion or period. Computational work of this study strictly follows the p.u voltage constraints for further computation of branch currents with relatively less iterations and computational time ${ }^{(25)}$.

\section{Mathematical model}

The distribution system planning process involves several steps including identification of the possible alternatives and evaluation of each alternative according to the formulated mathematical models and selection of most suitable alternatives, which forms the development strategy ${ }^{(26)}$. As a result in this study there are three general objectives which are identified and to be minimized: investment cost, operational cost and system reliability (which is evaluated by NSEC or customer outage cost). The relative goodness of each alternative can be measured in terms of the selected attributes of the planning task. The mathematical model presented in this study is dynamic in nature and reflects the technical and economical aspects of the network's elements during the whole planning process. Corresponding planning attributes are calculated for each planning period in case of multistage distribution system expansion ${ }^{(12)}$.

A distinctive model used in this study has large potential to satisfy the planning attributes. A load flow studies calculations in the distribution network planning task is taken into consideration for various purpose to check whether the network meets operational constraints, optimal or suitable size of feeder's conductors and selection of the feeder's conductors for the calculation of the investment cost and operational cost ${ }^{(27)}$. The main feature of load flow study calculations for network planning process is that it would be used multiple times and it must be very fast, accurate and takes comparatively less iterations to converge. In this study the radial load flow algorithm which based on very fundamental laws KCL and KVL is taken on the basis of backward and forward propagation method because of certain limitations of distribution network like high R/X ratio and radially of the distribution network ${ }^{(28)}$.

A mathematical model for MSDSP problem is expressed in terms of the objective function, such that overall investment cost should be minimum while operational constraints should not be violated. The objective functions are generally expressed mathematically ${ }^{(29)}$ as follows:

$$
\text { Minimum } Z=Z_{I}+Z_{O}+Z_{N S E C}
$$

Where

$Z_{I}=$ Total investment cost.

$Z_{O}=$ Total operational cost.

$Z_{N S E C}=$ Total system reliability cost in terms of NSEC.

\subsection{Distribution network expansion investment and operational cost formulation}

In this formulation the economical analysis of investment and operational cost involves the evaluation of annual investment cost. Total annual equivalent cost includes investment and operational cost together.

$$
T A C=A I C+A E C
$$

Where

$\mathrm{TAC}=$ Total annual equivalent cost.

$\mathrm{AIC}=$ Annual equivalent of expansion investment cost of power distribution network.

$\mathrm{AEC}=$ Annual equivalent of energy cost due to $\mathrm{I}^{2} \mathrm{R}$ losses in feeder's conductors.

\subsubsection{Annual expansion investment cost of power distribution network}

$$
A I C=\sum_{b} C_{n b}+\sum_{r} C_{r b}+\sum_{s w} C_{s w}+\sum_{s e} C_{s e}+\sum_{n s} C_{n}
$$


Above mathematical expression includes the cost of construction of the new branches, replacement of the existing branches, installation of the sectionalizing switches, expansion of existing substations and installation of new ones ${ }^{(30)}$.

Where

$C_{n b}=$ Cost of construction of the new feeders.

$C_{r b}=$ Cost of replacement of the branches with new ones.

$C_{s w}=$ Cost of installation of the sectionalizing switches.

$C_{n s}=$ Cost of installation of new substations.

$C_{s e}=$ Cost of expansion of the existing substations.

In general practice utility companies include the capital cost, depreciation cost, taxes, insurance and operational costs, maintenance expenses and annual fixed charge rate etc.

\subsubsection{Annual equivalent of operational cost of power distribution network}

The annual equivalent of energy cost due to $\mathrm{I}^{2} \mathrm{R}$ losses in the feeder's conductors can be expressed ${ }^{(31)}$ as:

$$
A E C=3 \times E_{c} \times D_{h} \times L_{l l f} \sum_{b=1}^{k} I_{b}^{2} \times R_{b}
$$

Where

$E_{C}=$ Energy prices according to the load levels: light, normal and peak.

$L_{l l f}=$ Load loss factor.

$I_{b}=$ Branch currents at each stage of planning.

$R_{b}=$ Feeders branch resistance.

$D_{h}=$ Duration in hours for each load level.

$D_{h l}=($ Duration in hours for light load level $)=2000 \mathrm{hrs} /$ year

$D_{h n=}$ (Duration in hours for normal load level) $=5700 \mathrm{hrs} /$ year

$D_{h p}=($ Duration in hours for peak load level $)=1000 \mathrm{hrs} /$ year

$$
L_{l l f}=\alpha \times L_{d}+\beta \times L_{d}^{2}
$$

Where

$L_{d}=$ Load factor.

Load factor for light load condition $=0.65$

Load factor for normal load condition $=0.85$

Load factor for peak load condition $=1.0$

The values of constants $\alpha$ and $\beta$ depend upon the categories of load such as domestic, commercial and industrial loads. In this study energy prices to evaluate the cost of losses are $\$ 51 / \mathrm{MWh}, \$ 83 / \mathrm{MWh}$ and $\$ 100 / \mathrm{MWh}$ for light, normal and peak load conditions respectively.

\subsection{Reliability cost of power distribution system network}

A mathematical function is used to evaluate the reliability of the distribution system network in terms of the non-supplied energy cost (NSEC) for the loads of the sections where the contingency occurred permanently ${ }^{(32)}$. From the point of view of planning and design to make the NSEC minimum, optimal and minimum number of sectionalizing switches are installed in the feeder sections of the network, which is directly related to the investment cost ${ }^{(33)}$. Along with the installation of the sectionalizing switches tie lines are also installed between the neighbouring feeders originated from the same substation or originated from the different substations. During the occurrence of contingency the faulty sections of the feeder can be operated in restored state for some priority loads of the faulty section of the feeder ${ }^{(34)}$. Thus the main concern is that the minimum number of customers should be affected by the outage or faults considering the priority of each class of customers like residential, commercial, industrial, hospitals and schools. Mathematical model for the evaluation of power distribution system reliability is represented in terms of the cost of non-supplied energy for each feeder of the distribution system in each network expansion stage.

2.2.1 Annual equivalent of non-supplied energy cost in the form of annual interruption cost Objective Function for Evaluation of Reliability

$$
\left(N S E C_{p p}\right)=\sum_{u}^{p p} A I C_{u}
$$


Where

$A I C_{u}=$ Annual interruption cost

$p p=$ Sets of periods of planning horizons, $p p \varepsilon\{1,2,3 \ldots\}$

Function for the cost of non-supplied energy of the feeder section where the fault occurred

Cost of non-supplied energy for total outage time $\left(C_{u}^{T O}\right)$

$$
C_{u}^{T O}=\left(C R R \times L R_{u}+C R C \times L C_{u}+C R I \times L I_{U}\right) \times L T_{U} \times \gamma_{u}^{N S E C}
$$

Cost of restored energy of the feeders section where the fault occurred $\left(C_{u}^{R E S}\right)$

Cost of restored energy after the identification and isolation of the faulty section of the feeder $\left(C_{u}^{T O}\right)$

$$
C_{u}^{R E S}=\sum_{n \in R E S}\left(C C R \times L R_{n}+C R C \times L C_{n u}+C R I \times L I_{n}\right) \times L T_{n} \times \gamma_{n}^{N S E C}
$$

Total loss of cost due to the outage

$$
\mathrm{C}_{\mathrm{u}}^{\mathrm{TNSEC}}=\mathrm{C}_{\mathrm{u}}^{\mathrm{TO}}+\mathrm{C}_{\mathrm{u}}^{\mathrm{NRES}}
$$

Where

$\gamma=$ Annual interst rate

$L T_{u}=$ Total load of the feeder section where fault occurred.

$L T_{n}=$ Total load of the feeder section restored where fault occurred.

$L T_{m}=$ Total load of the feeder section not restored where fault occurred.

$$
L T_{U}=L T_{n}+L T_{M}
$$

Let total outage time $=T_{u}$

Outage time for $L T_{U}=T_{1}$

Restoration time for $L T_{n}=T_{2}=T_{1}$

Non restored time for $L T_{m}=\mathrm{T}_{3}$

$$
T_{u}=T_{1}+T_{3}
$$

Formulation of annual interest rate and annual section load growth function for computation of the NSEC, the expression is as follows.

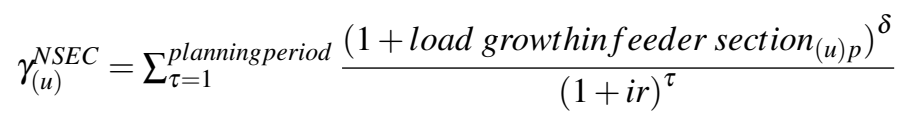

$$
\begin{aligned}
& Z_{N S E C}=\lambda_{u} \times L_{u} \times \sum_{p \in p p} C_{u}^{T N S E C}
\end{aligned}
$$

Where, $\lambda_{u} \& L_{u}$ are the rate of failure of permanent fault and length of the feeder section respectively.

The technical and operational constraints including power quality of the supply are as follows:

- Voltage magnitude contraints

$$
V_{\min }<V_{i, k, p}<V_{\operatorname{maxi}} p \in p p
$$

-Current capacities of the feeders

$$
I_{i j, k, p} \leq I_{i j, p}^{\max }
$$

-Capacities of the substations

$$
0 \leq \sum_{S 1} S_{i, k, p}^{l o a d}+\sum_{s 2} S_{i j, k, p}^{l o s s e s} \leq S_{s s}
$$




\section{Solution techniques}

In this study an optimal approach is applied to find out the solution of MSDSP problem by considering investment cost, operational cost and reliability of the distribution network. To determine the operational or technical losses a radial backward and forward sweep based load flow technique is used ( Tables 1 and 7). The proposed MSDSP problem is tested for 11kV, 50-bus distribution system network which initially has only one substation. The initial stage of distribution system network is shown in ( Figure 1) along all forthcoming load points. All possible optimal routes of feeders or cables, expansion of existing substations and construction of new substations with suitable locations are considered for period wise expansion of network ( Tables 3 and 5). Although it is also observed that some load points follow the same load levels ( Table 2 ), which means that no load growth at some load points.

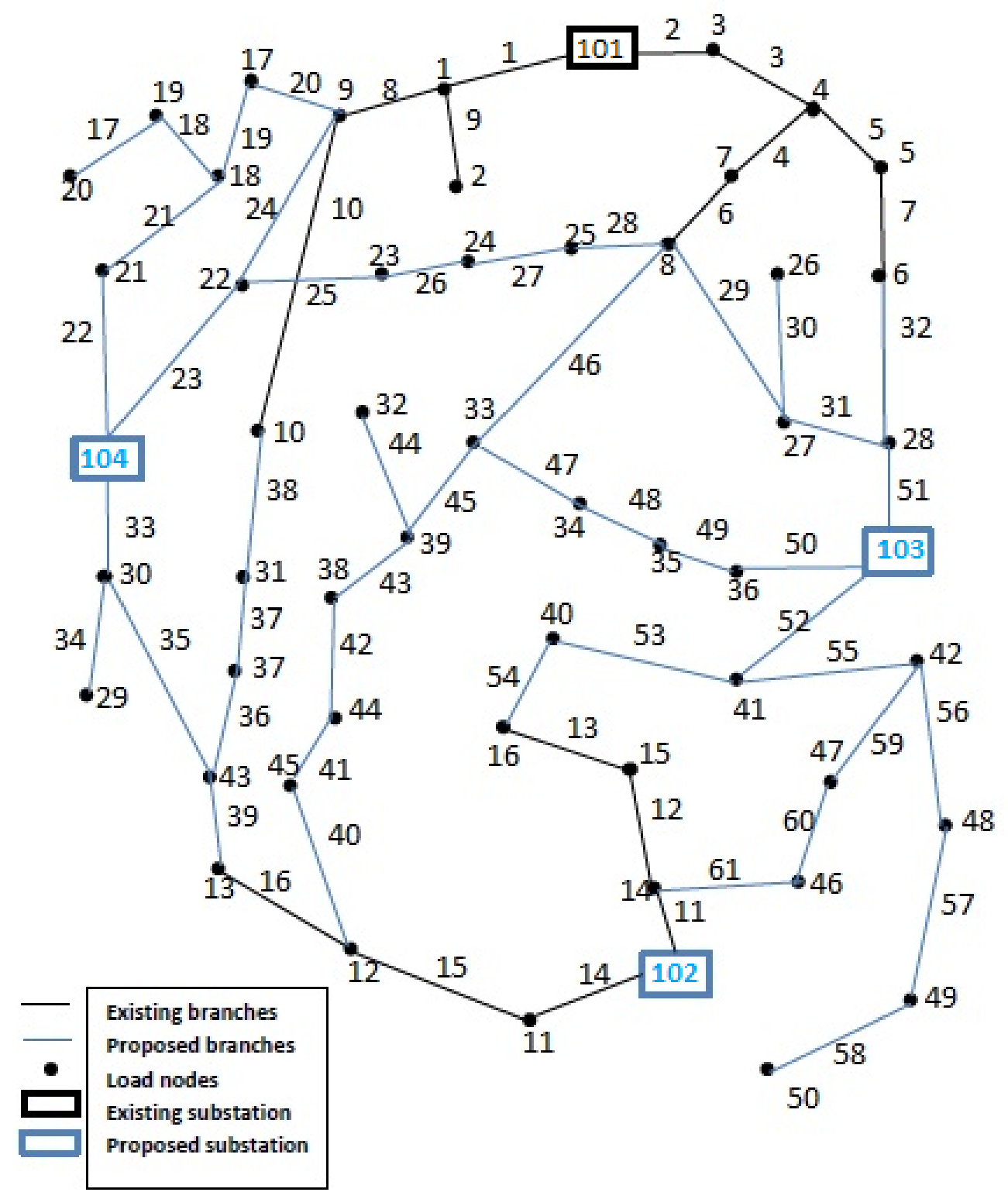

Fig 1. Initial stage of distribution system (4)

The proposed MSDSP problem is analyzed by the following solution strategies and procedures; expansion of the system network according to optimal routing algorithm for feeders routes, installation of new conductors for new load points and 
replacement of existing branch conductors for the expansion of the network for the years of planning horizon. To measure the system reliability, the allocation of the sectionalizing switches and installation of the tie lines between the feeders of same substations and/or between the different substations have been done for restoration of the load during permanent fault conditions in feeder sections ( Tables 4 and 6). The maximum and minimum voltage limits for each node are $0.95 \mathrm{and} 1.05 \mathrm{pu}$ respectively, and the reference voltage for substations are taken constant $1.0 \mathrm{pu}$. The voltage of each node points are computed through the backward and forward load flow studies. The annual rate of interest is taken $10 \%$ as per the normal rate of interest of banking sectors of the countries. The rate of permanent faults is 0.4 faults $/ \mathrm{km} /$ year for the feeder's conductor under network contingency conditions. For the development of programs of proposed mathematical model and computational work MATLAB R2013a software is used.

\section{Results and Discussion}

In order to deal with the practical and real time MSDSP problem, a distinctive multi- objective model is developed in this work. The proposed mathematical model focuses on the technical, economical and system reliability issues of the electric power distribution system network. The realization of the proposed mathematical model is appraised and demonstrated on $11 \mathrm{kV}, 50$-bus distribution system network test data with existing substation and proposed substations. The initial stage of $11 \mathrm{kV}$, 50 - bus distribution system network is shown in the (Figure 1) and the test data of 50- bus distribution system network is presented in ( Tables 1, 2, 3, 4, 5, 6, 7, 8 and 9). The multistage planning period is considered for 15 years and it is divided into three equal periods of 5 year each. Further multistage expansion of distribution network is done by considering the various possible solutions like reconductoring of the existing feeders, construction of new feeders and/or restructuring of the initial stage of distribution network. Load flow studies results are computed for each MSDSP planning period of expansion with every possible solution discussed in solution techniques. ( Figure 2 ) demonstrates that the real power $(\mathrm{kW})$, reactive power (kVAr) and apparent power $(\mathrm{kVA})$ demand for each planning period and it verifies the dynamic nature of MSDSP problem. Evaluation of all objective functions, investment cost, operational cost and system reliability has been done using the equations (1) - (13) respectively.

( Figure 3 ) demonstrates the most appropriate solutions obtained for the each sub objective functions of the developed mathematical model such as investment cost, operational cost and the system reliability in terms of NSEC for each MSDSP period. Also, from ( Figure 4 ) it is observed that the results obtained for total investment cost , total operational cost and total NSEC for all three planning periods and overall cost of investment/ total system cost (i.e. the sum of total investment cost, total operational cost and total NSEC) for the complete expansion of multistage distribution system network. These obtained results demonstrate the most appropriate/ suitable solution from the point of view of technical, investment and overall system reliability. The results obtained in ( Figures 3 and 4) also demonstrate that it is the most economical and reliable network expansion for MSDSP of power distribution system network and clearly shows the goodness of the results. In this proposed work the corresponding bus nodes voltages in pu for each period of network expansion satisfy the considered technical constraints of voltage profiles (maximum and minimum voltage limits for each node are 0.95 and 1.05 pu respectively), which shows the adequacy and effectiveness of the proposed distinctive multi- objective model for a practical and real time MSDSP problem. As, we can observe from the ( Figure 5), that the bus nodes voltage profiles limits (minimum and maximum) in pu lies in the assumed limits for each period of network expansion. Further the corresponding bus nodes voltages in pu are shown in ( Figure 6 ), for the MSDSP planning period 1, it is observed that each bus nodes voltages satisfy the considered technical constraint of voltage profiles. Similar observations can be made from the (Figures 7 and 8 ) for the network expansion period 2 and period 3 respectively. Hence the proposed approach and the simulation results demonstrate that the period wise expansion of MSDSP for $11 \mathrm{kV}, 50$-bus distribution system provides the optimal solution by considering the investment cost, operational cost and system reliability of the distribution system network.

Table 1. Cable/ Conductor Data

\begin{tabular}{lll}
\hline Category of cables/ conductors & Current capacity $(\mathrm{A})$ & Impedance $(\Omega / \mathrm{km})$ \\
\hline 1 & 150 & $0.3655+\mathrm{j} 0.2520$ \\
2 & 250 & $0.2359+\mathrm{j} 0.2402$ \\
3 & 350 & $0.1827+\mathrm{j} 0.1260$ \\
4 & 400 & $0.1460+\mathrm{j} 0.1233$ \\
5 & 500 & $0.1180+\mathrm{j} 0.1201$ \\
6 & 600 & $0.9660+\mathrm{j} 0.1201$ \\
\hline
\end{tabular}


Table 2. Load data at load nodes for different planning period

\begin{tabular}{|c|c|c|c|c|c|c|c|c|c|c|c|c|}
\hline \multirow[t]{2}{*}{$\begin{array}{l}\text { Bus } \\
\text { Node } \\
\text { no. }\end{array}$} & \multicolumn{2}{|c|}{ Period 1} & \multicolumn{2}{|c|}{ Period 2} & \multicolumn{2}{|c|}{ Perid 3} & \multicolumn{3}{|c|}{$\begin{array}{l}\text { Category of customers } \\
\text { and their respective } \\
\text { loading in } \% \text { at Bus Node }\end{array}$} & \multicolumn{3}{|c|}{$\begin{array}{l}\text { Annual load growth at each } \\
\text { node in }(\%)\end{array}$} \\
\hline & $\begin{array}{l}\mathrm{P}, \\
\mathrm{kW}\end{array}$ & $\begin{array}{l}\text { Q, } \\
\text { kVAr }\end{array}$ & $\begin{array}{l}\mathrm{P}, \\
\mathrm{kW}\end{array}$ & $\begin{array}{l}\text { Q, } \\
\text { kVAr }\end{array}$ & $\begin{array}{l}\mathrm{P}, \\
\mathrm{kW}\end{array}$ & $\begin{array}{l}\text { Q, } \\
\text { kVAr }\end{array}$ & Res. & Comm. & Ind. & Period 1 & Period 2 & Period 3 \\
\hline 1 & 2376 & 1150.72 & 2736 & 1325.12 & 3024 & 1464.56 & 70 & 20 & 10 & 2.445 & 2.862 & 2.022 \\
\hline 2 & 792 & 383.6 & 936 & 453.36 & 1080 & 523.04 & 60 & 20 & 20 & 3.152 & 3.398 & 2.903 \\
\hline 3 & 288 & 139.52 & 360 & 174.32 & 504 & 244.08 & 80 & 20 & 0 & 5.79 & 4.564 & 6.961 \\
\hline 4 & 1008 & 488.16 & 1368 & 662.56 & 792 & 383.6 & 75 & 10 & 15 & 0.981 & 6.298 & -10.355 \\
\hline 5 & 1440 & 697.44 & 1656 & 802 & 1872 & 906.64 & 0 & 0 & 100 & 2.659 & 2.835 & 2.482 \\
\hline 6 & 432 & 209.2 & 504 & 244.08 & 504 & 244.08 & 65 & 25 & 10 & 1.614 & 3.131 & 0 \\
\hline 7 & 144 & 69.76 & 360 & 174.32 & 720 & 348.72 & 50 & 50 & 0 & 17.608 & 20.112 & 14.87 \\
\hline 8 & 1080 & 523.04 & 1224 & 592.8 & 1368 & 662.56 & 70 & 20 & 10 & 2.393 & 2.535 & 2.249 \\
\hline 9 & 1368 & 662.56 & 1440 & 697.44 & 864 & 418.48 & 80 & 20 & 0 & 0.981 & 1.031 & -9.712 \\
\hline 10 & 1440 & 697.44 & 1728 & 836.88 & 2088 & 1011.28 & 60 & 25 & 15 & 3.786 & 3.714 & 3.857 \\
\hline 11 & 144 & 69.76 & 216 & 104.64 & 216 & 104.64 & 70 & 30 & 0 & 4.564 & 8.447 & 0 \\
\hline 12 & 720 & 348.72 & 1152 & 557.92 & 1296 & 627.68 & 30 & 70 & 0 & 6.382 & 9.856 & 2.384 \\
\hline 13 & 648 & 313.84 & 720 & 348.72 & 792 & 383.6 & 70 & 20 & 10 & 2.027 & 2.13 & 1.924 \\
\hline 14 & 576 & 278.96 & 648 & 313.84 & 720 & 348.72 & 60 & 20 & 20 & 2.257 & 2.384 & 2.13 \\
\hline 15 & 720 & 348.72 & 864 & 418.48 & 1008 & 488.16 & 80 & 20 & 0 & 3.424 & 3.714 & 3.131 \\
\hline 16 & 936 & 453.36 & 1080 & 523.04 & 1368 & 662.56 & 75 & 10 & 15 & 3.89 & 2.903 & 4.841 \\
\hline 17 & 360 & 174.32 & 432 & 209.2 & 504 & 244.08 & 0 & 0 & 100 & 3.424 & 3.714 & 3.131 \\
\hline 18 & 648 & 313.84 & 720 & 348.72 & 864 & 418.48 & 65 & 25 & 10 & 2.934 & 2.13 & 3.714 \\
\hline 19 & 720 & 348.72 & 864 & 418.48 & 1008 & 488.16 & 50 & 50 & 0 & 3.424 & 3.714 & 3.131 \\
\hline 20 & 360 & 174.32 & 504 & 244.08 & 576 & 278.96 & 70 & 20 & 10 & 4.92 & 6.961 & 2.707 \\
\hline 21 & 360 & 174.32 & 1152 & 557.92 & 1296 & 627.68 & 70 & 30 & 0 & 16.679 & 26.191 & 2.384 \\
\hline 22 & 360 & 174.32 & 720 & 348.72 & 792 & 388.6 & 60 & 25 & 15 & 9.161 & 14.87 & 1.924 \\
\hline 23 & 360 & 174.32 & 648 & 313.84 & 720 & 348.72 & 70 & 20 & 10 & 7.797 & 12.475 & 2.13 \\
\hline 24 & 360 & 174.32 & 288 & 139.52 & 360 & 174.32 & 60 & 20 & 20 & 0.981 & -4.365 & 4.564 \\
\hline 25 & 432 & 209.2 & 576 & 278.96 & 648 & 313.84 & 80 & 20 & 0 & 4.213 & 5.922 & 2.384 \\
\hline 26 & 0 & 0 & 576 & 278.96 & 864 & 418.48 & 75 & 10 & 15 & 0 & 1.172 & 8.447 \\
\hline 27 & 0 & 0 & 864 & 418.48 & 1080 & 523.04 & 0 & 0 & 100 & 0 & 1.172 & 4.564 \\
\hline 28 & 288 & 139.52 & 360 & 174.32 & 504 & 244.08 & 45 & 55 & 0 & 5.79 & 4.564 & 6.961 \\
\hline 29 & 432 & 209.2 & 648 & 313.84 & 1008 & 488.16 & 50 & 50 & 0 & 8.846 & 8.447 & 9.239 \\
\hline 30 & 1440 & 697.44 & 1656 & 802 & 1872 & 906.64 & 70 & 30 & 0 & 2.659 & 2.835 & 2.482 \\
\hline 31 & 432 & 209.2 & 504 & 244.08 & 504 & 244.08 & 80 & 20 & 0 & 1.614 & 3.131 & 0 \\
\hline 32 & 0 & 0 & 1080 & 523.04 & 1224 & 592.8 & 60 & 25 & 15 & 0 & 1.172 & 2.535 \\
\hline 33 & 1296 & 627.68 & 1656 & 802 & 2088 & 1011.28 & 70 & 20 & 10 & 4.885 & 5.025 & 4.745 \\
\hline 34 & 648 & 313.84 & 720 & 348.72 & 864 & 418.48 & 60 & 20 & 20 & 2.934 & 2.13 & 3.714 \\
\hline 35 & 0 & 0 & 0 & 0 & 648 & 313.84 & 80 & 20 & 0 & 0 & 0 & 0.787 \\
\hline 36 & 144 & 69.76 & 144 & 69.76 & 216 & 104.64 & 75 & 10 & 15 & 4.564 & 0 & 8.447 \\
\hline 37 & 720 & 348.72 & 1152 & 557.92 & 1512 & 732.32 & 0 & 0 & 100 & 7.807 & 9.856 & 5.589 \\
\hline 38 & 0 & 0 & 0 & 0 & 792 & 383.6 & 65 & 25 & 10 & 0 & 0 & 0.787 \\
\hline 39 & 576 & 278.96 & 648 & 313.84 & 720 & 348.72 & 20 & 80 & 0 & 2.257 & 2.384 & 2.13 \\
\hline 40 & 720 & 348.72 & 864 & 418.48 & 1008 & 488.16 & 70 & 20 & 10 & 3.424 & 3.714 & 3.131 \\
\hline 41 & 216 & 104.64 & 360 & 174.32 & 648 & 313.84 & 80 & 20 & 0 & 11.629 & 10.757 & 12.475 \\
\hline 42 & 0 & 0 & 0 & 0 & 864 & 418.48 & 60 & 25 & 15 & 0 & 0 & 1.362 \\
\hline 43 & 0 & 0 & 0 & 0 & 936 & 453.36 & 70 & 20 & 10 & 0 & 0 & 1.362 \\
\hline 44 & 360 & 174.32 & 720 & 348.72 & 1008 & 488.16 & 60 & 20 & 20 & 11.196 & 14.87 & 6.961 \\
\hline 45 & 360 & 174.32 & 360 & 174.32 & 576 & 278.96 & 80 & 20 & 0 & 5.387 & 0 & 9.856 \\
\hline 46 & 0 & 0 & 1152 & 557.92 & 1296 & 627.68 & 75 & 10 & 15 & 0 & 1.172 & 2.384 \\
\hline 47 & 360 & 174.32 & 360 & 174.32 & 720 & 348.72 & 0 & 0 & 100 & 8.447 & 0 & 14.87 \\
\hline 48 & 360 & 174.32 & 432 & 209.2 & 576 & 278.96 & 65 & 25 & 10 & 4.841 & 3.714 & 5.922 \\
\hline 49 & 0 & 0 & 432 & 209.2 & 360 & 174.32 & 50 & 50 & 0 & 0 & 1.172 & -3.581 \\
\hline 50 & 0 & 0 & 0 & 0 & 576 & 278.96 & 70 & 20 & 10 & 0 & 0 & 0.981 \\
\hline
\end{tabular}


Table 3. Cost to install/ construct and replace the cable/conductor $(\mathrm{k} \$ / \mathrm{km})$

\begin{tabular}{|c|c|c|c|c|c|c|}
\hline \multirow{2}{*}{$\begin{array}{l}\text { New Installation / Replacement by } \\
\text { another cable }\end{array}$} & \multicolumn{6}{|c|}{ Types of Conductors/Cables } \\
\hline & $\mathrm{C} 1$ & $\mathrm{C} 2$ & $\mathrm{C} 3$ & $\mathrm{C} 4$ & C5 & C6 \\
\hline 0 & 20.00 & 30.00 & 42.00 & 50.00 & 67.00 & 85.00 \\
\hline 1 & & 23.00 & 37.00 & 40.00 & 58.00 & 76.00 \\
\hline 2 & & & 30.00 & 35.00 & 50.00 & 66.00 \\
\hline 3 & & & & 29.00 & 43.00 & 53.00 \\
\hline 4 & & & & & 35.00 & 43.00 \\
\hline 5 & & & & & & 38.00 \\
\hline
\end{tabular}

Table 4. Cost of interruption for the evaluation of NSEC or say system reliability

\begin{tabular}{lll}
\hline \multirow{2}{*}{ Customer Category } & \multicolumn{2}{c}{ Interruption cost (\$/MW/year) } \\
\cline { 2 - 3 } & Restoration (15min.) & Repair and maintenance $(120$ min.) \\
\hline Residential & 40.00 & 2000.00 \\
Commercial & 1200.00 & 12800.00 \\
Industrial & 1600.00 & 10400.00 \\
\hline
\end{tabular}

Table 5. Substation data

\begin{tabular}{lllll}
\hline Bus No. & Initially installed capacity & New capacit & Construction cost (k\$/MVA) & $\begin{array}{l}\text { Expansion cost } \\
(\mathrm{k} \$ \text { /MVA })\end{array}$ \\
\hline Exiting & & & & 1400.0 \\
101 & 16.7 & 33.4 & - & 1200.0 \\
102 & 16.7 & 30.0 & - & \\
103 & - & 22.2 & 3000.0 & \\
104 & - & 22.2 & 3000.0 & \\
\hline
\end{tabular}

Table 6. Load level, load factor, load level duration and energy price

\begin{tabular}{lllll}
\hline Sr. no & Load levels & Load factor & Duration $($ hrs/year $)$ & Energy price $(\$ / \mathrm{MWh})$ \\
\hline 1. & Light & 0.65 & 2000 & 51 \\
2. & Normal & 0.80 & 5700 & 83 \\
3. & Peak & 1.0 & 1000 & 100 \\
\hline
\end{tabular}

Table 7. Feeder branch data

\begin{tabular}{llll}
\hline Sr. No. & Brach no. & Cable type & Length in $(\mathrm{m})$ \\
\hline 1 & 1 & 2 & 562.00 \\
2 & 2 & 2 & 436.00 \\
3 & 3 & 2 & 624.00 \\
4 & 4 & 2 & 500.00 \\
5 & 5 & 2 & 624.00 \\
6 & 6 & 2 & 624.00 \\
7 & 7 & 2 & 500.00 \\
8 & 8 & 2 & 686.00 \\
9 & 9 & 2 & 624.00 \\
10 & 10 & 2 & 1436.00 \\
11 & 11 & 2 & 750.00 \\
12 & 12 & 2 & 750.00 \\
13 & 13 & 2 & 562.00 \\
14 & 14 & 2 & 562.00 \\
15 & 15 & 2 & 624.00 \\
16 & 16 & 2 & 874.00 \\
\hline
\end{tabular}




\begin{tabular}{|c|c|c|c|}
\hline \multicolumn{4}{|c|}{ Table 7 continued } \\
\hline 17 & 17 & 0 & 624.00 \\
\hline 18 & 18 & 0 & 500.00 \\
\hline 19 & 19 & 0 & 812.00 \\
\hline 20 & 20 & 0 & 860.00 \\
\hline 21 & 21 & 0 & 624.00 \\
\hline 22 & 22 & 0 & 500.00 \\
\hline 23 & 23 & 0 & 750.00 \\
\hline 24 & 24 & 0 & 936.00 \\
\hline 25 & 25 & 0 & 686.00 \\
\hline 26 & 26 & 0 & 562.00 \\
\hline 27 & 27 & 0 & 436.00 \\
\hline 28 & 28 & 0 & 562.00 \\
\hline 29 & 29 & 0 & 750.00 \\
\hline 30 & 30 & 0 & 686.00 \\
\hline 31 & 31 & 0 & 624.00 \\
\hline 32 & 32 & 0 & 1000.00 \\
\hline 33 & 33 & 0 & 562.00 \\
\hline 34 & 34 & 0 & 624.00 \\
\hline 35 & 35 & 0 & 812.00 \\
\hline 36 & 36 & 0 & 500.00 \\
\hline 37 & 37 & 0 & 374.00 \\
\hline 38 & 38 & 0 & 624.00 \\
\hline 39 & 39 & 0 & 750.00 \\
\hline 40 & 40 & 0 & 500.00 \\
\hline 41 & 41 & 0 & 436.00 \\
\hline 42 & 42 & 0 & 624.00 \\
\hline 43 & 43 & 0 & 686.00 \\
\hline 44 & 44 & 0 & 812.00 \\
\hline 45 & 45 & 0 & 562.00 \\
\hline 46 & 46 & 0 & 936.00 \\
\hline 47 & 47 & 0 & 374.00 \\
\hline 48 & 48 & 0 & 436.00 \\
\hline 49 & 49 & 0 & 436.00 \\
\hline 50 & 50 & 0 & 500.00 \\
\hline 51 & 51 & 0 & 624.00 \\
\hline 52 & 52 & 0 & 624.00 \\
\hline 53 & 53 & 0 & 750.00 \\
\hline 54 & 54 & 0 & 500.00 \\
\hline 55 & 55 & 0 & 750.00 \\
\hline 56 & 56 & 0 & 500.00 \\
\hline 57 & 57 & 0 & 750.00 \\
\hline 58 & 58 & 0 & 436.00 \\
\hline 59 & 59 & 0 & 624.00 \\
\hline 60 & 60 & 0 & 624.00 \\
\hline 61 & 61 & 0 & 686.00 \\
\hline 62 & - & - & - \\
\hline 63 & - & - & - \\
\hline
\end{tabular}

Table 8. Annual load growth for nodes 1 to 23 in \%

\begin{tabular}{llll}
\hline Node & Period 1 & Period 2 & Period 3 \\
\hline 101 & 0 & 0 & 0 \\
102 & 0 & 0 & 0 \\
103 & 0 & 0 & 0 \\
104 & 0 & 0 & 0 \\
1 & 2.445 & 2.862 & 2.022 \\
\hline
\end{tabular}




\begin{tabular}{llll}
\hline Table 8 continued & \multicolumn{3}{r}{} \\
\hline 2 & 3.152 & 3.398 & 2.903 \\
3 & 5.79 & 4.564 & 6.961 \\
4 & 0.981 & 6.298 & -10.355 \\
5 & 2.659 & 2.835 & 2.482 \\
6 & 1.614 & 3.131 & 0 \\
7 & 17.608 & 20.112 & 14.87 \\
8 & 2.393 & 2.535 & 2.249 \\
9 & 0.981 & 1.031 & -9.712 \\
10 & 3.786 & 3.714 & 3.857 \\
11 & 4.564 & 8.447 & 0 \\
12 & 6.382 & 9.856 & 2.384 \\
13 & 2.027 & 2.13 & 1.924 \\
14 & 2.257 & 2.384 & 2.13 \\
15 & 3.424 & 3.714 & 3.131 \\
16 & 3.89 & 2.903 & 4.841 \\
17 & 3.424 & 3.714 & 3.131 \\
18 & 2.934 & 2.13 & 3.714 \\
19 & 3.424 & 3.714 & 3.131 \\
20 & 4.92 & 6.961 & 2.707 \\
21 & 16.679 & 26.191 & 2.384 \\
22 & 9.161 & 14.87 & 1.924 \\
23 & 7.797 & 12.475 & 2.13 \\
\hline
\end{tabular}

Table 9. Annual load growth for nodes 24 to 50 in \%

\begin{tabular}{|c|c|c|c|}
\hline Node & Period 1 & Period 2 & Period 3 \\
\hline 24 & 0.981 & -4.365 & 4.564 \\
\hline 25 & 4.213 & 5.922 & 2.384 \\
\hline 26 & 0 & 1.172 & 8.447 \\
\hline 27 & 0 & 1.172 & 4.564 \\
\hline 28 & 5.79 & 4.564 & 6.961 \\
\hline 29 & 8.846 & 8.447 & 9.239 \\
\hline 30 & 2.659 & 2.835 & 2.482 \\
\hline 31 & 1.614 & 3.131 & 0 \\
\hline 32 & 0 & 1.172 & 2.535 \\
\hline 33 & 4.885 & 5.025 & 4.745 \\
\hline 34 & 2.934 & 2.13 & 3.714 \\
\hline 35 & 0 & 0 & 0.787 \\
\hline 36 & 4.564 & 0 & 8.447 \\
\hline 37 & 7.807 & 9.856 & 5.589 \\
\hline 38 & 0 & 0 & 0.787 \\
\hline 39 & 2.257 & 2.384 & 2.13 \\
\hline 40 & 3.424 & 3.714 & 3.131 \\
\hline 41 & 11.629 & 10.757 & 12.475 \\
\hline 42 & 0 & 0 & 1.362 \\
\hline 43 & 0 & 0 & 1.362 \\
\hline 44 & 11.196 & 14.87 & 6.961 \\
\hline 45 & 5.387 & 0 & 9.856 \\
\hline 46 & 0 & 1.172 & 2.384 \\
\hline 47 & 8.447 & 0 & 14.87 \\
\hline 48 & 4.841 & 3.714 & 5.922 \\
\hline 49 & 0 & 1.172 & -3.581 \\
\hline 50 & 0 & 0 & 0.981 \\
\hline
\end{tabular}




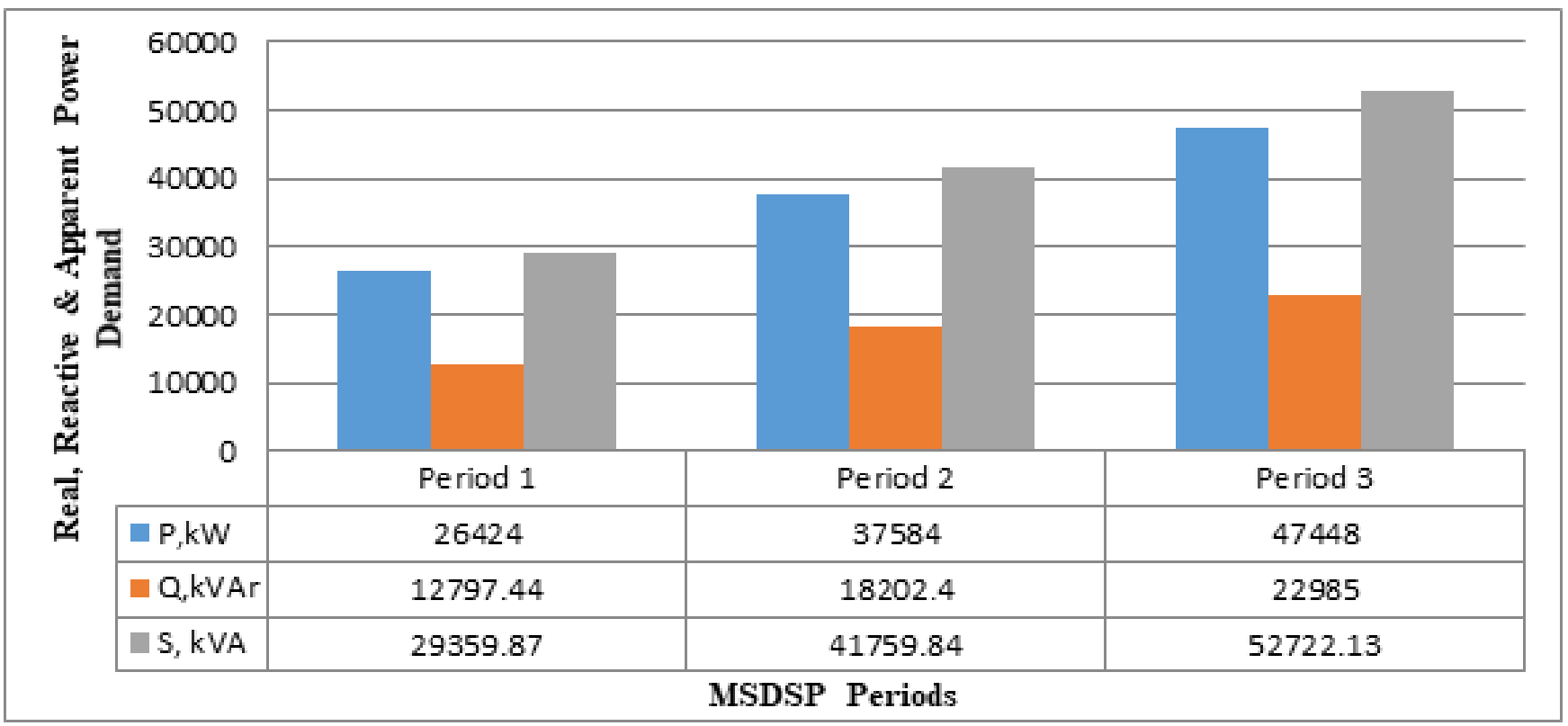

Fig 2. Real Power (kW), Reactive Power (kVAr) and Apparent Power (kVA) demand for each MSDSP period

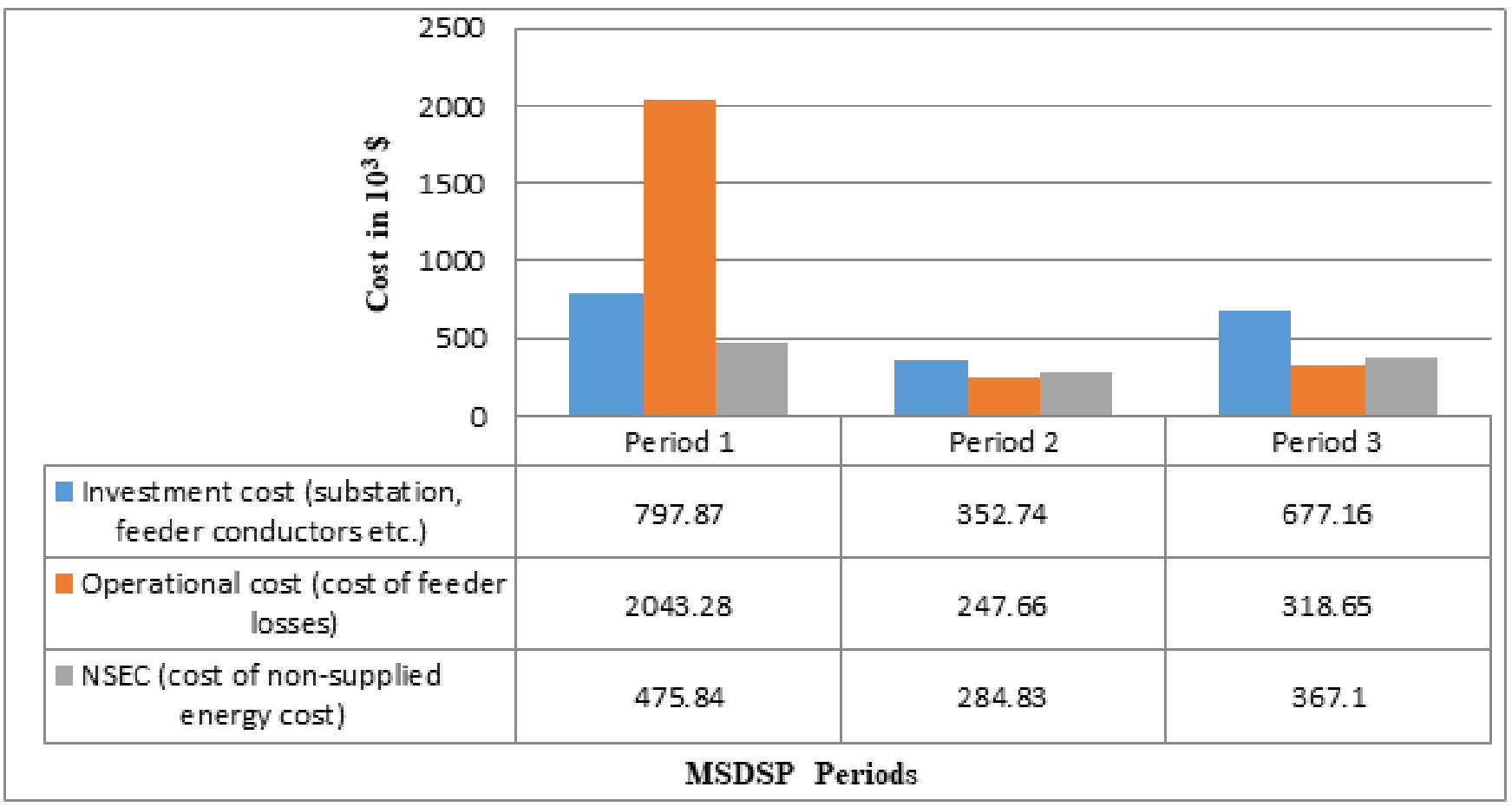

Fig 3. Investments cost, operational cost and NSEC for each MSDSP period. 


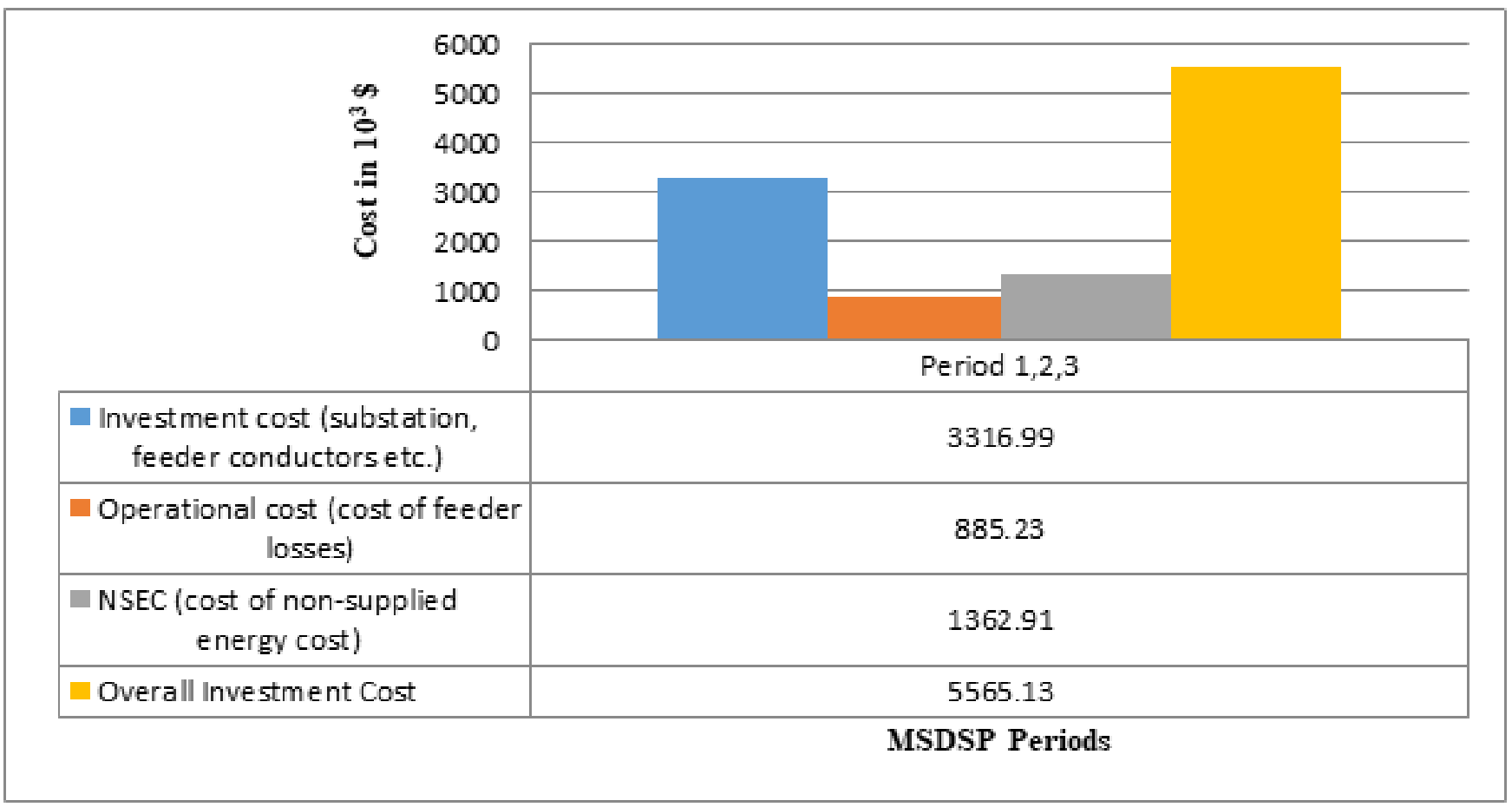

Fig 4. Total investments cost, total operational cost, total NSEC and overall cost of the system for all three periods of network expansion.

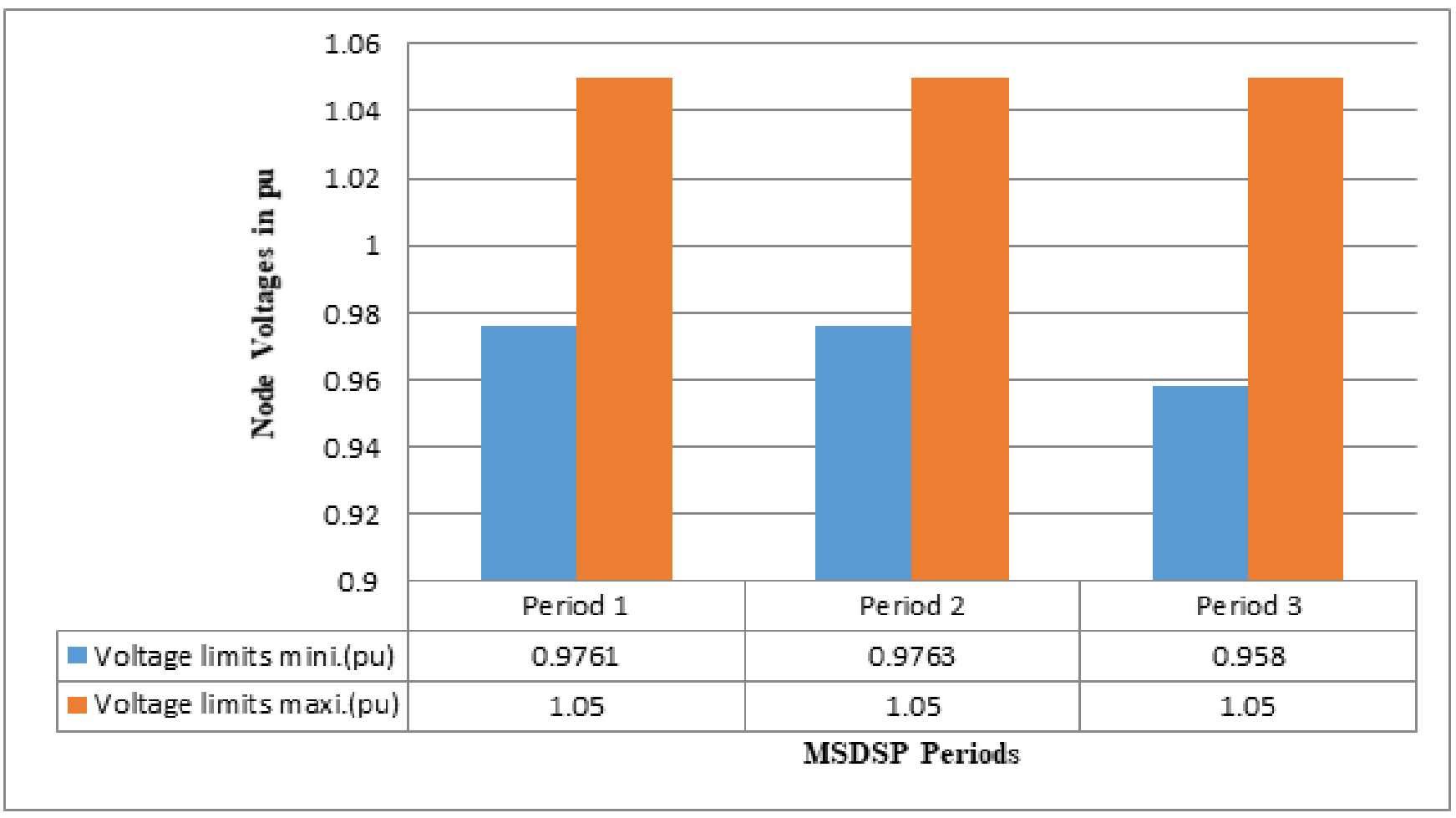

Fig 5. Node voltages profiles limits (minimum and maximum) in pu for each period of network expansion

Thus, the results shown in this work for MSDSP problem satisfies the technical, economical and reliability aspects with power quality issues of radial power distribution network. The demonstrated results will definitely motivate and will help the real 


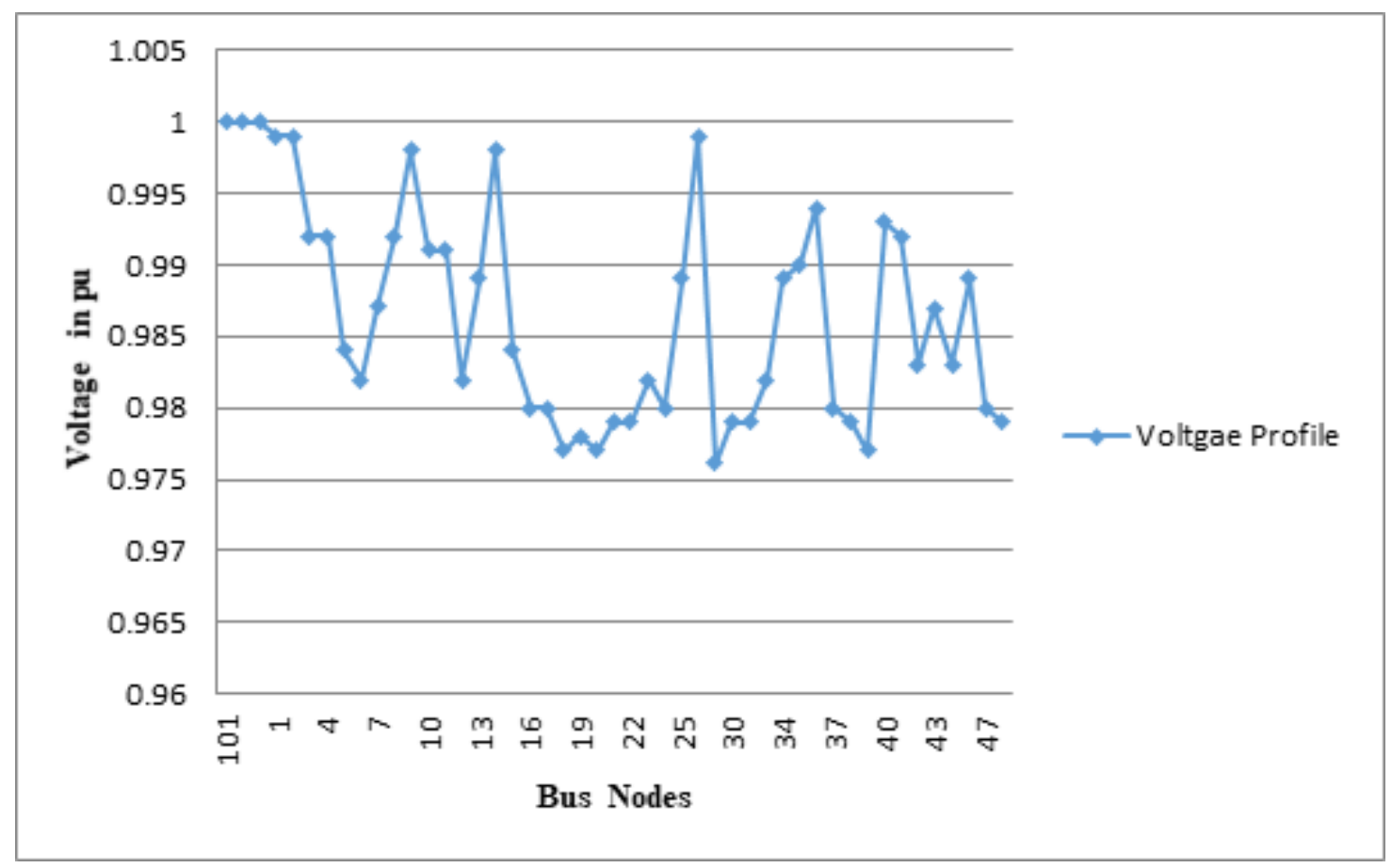

Fig 6. Voltage profiles of bus nodes after the network expansion of period 1

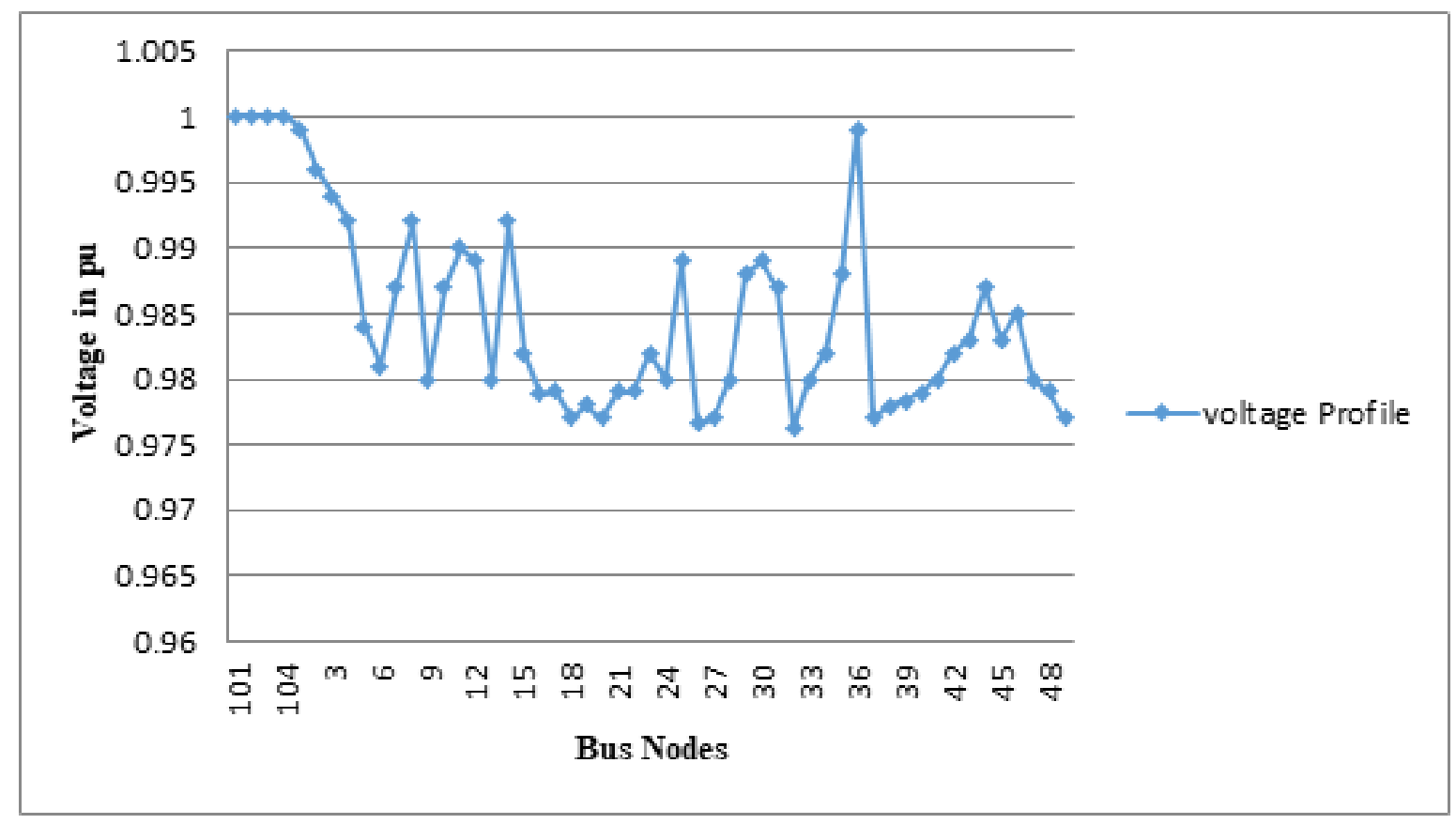

Fig 7. Voltage profile of bus nodes after the network expansion of period 2 


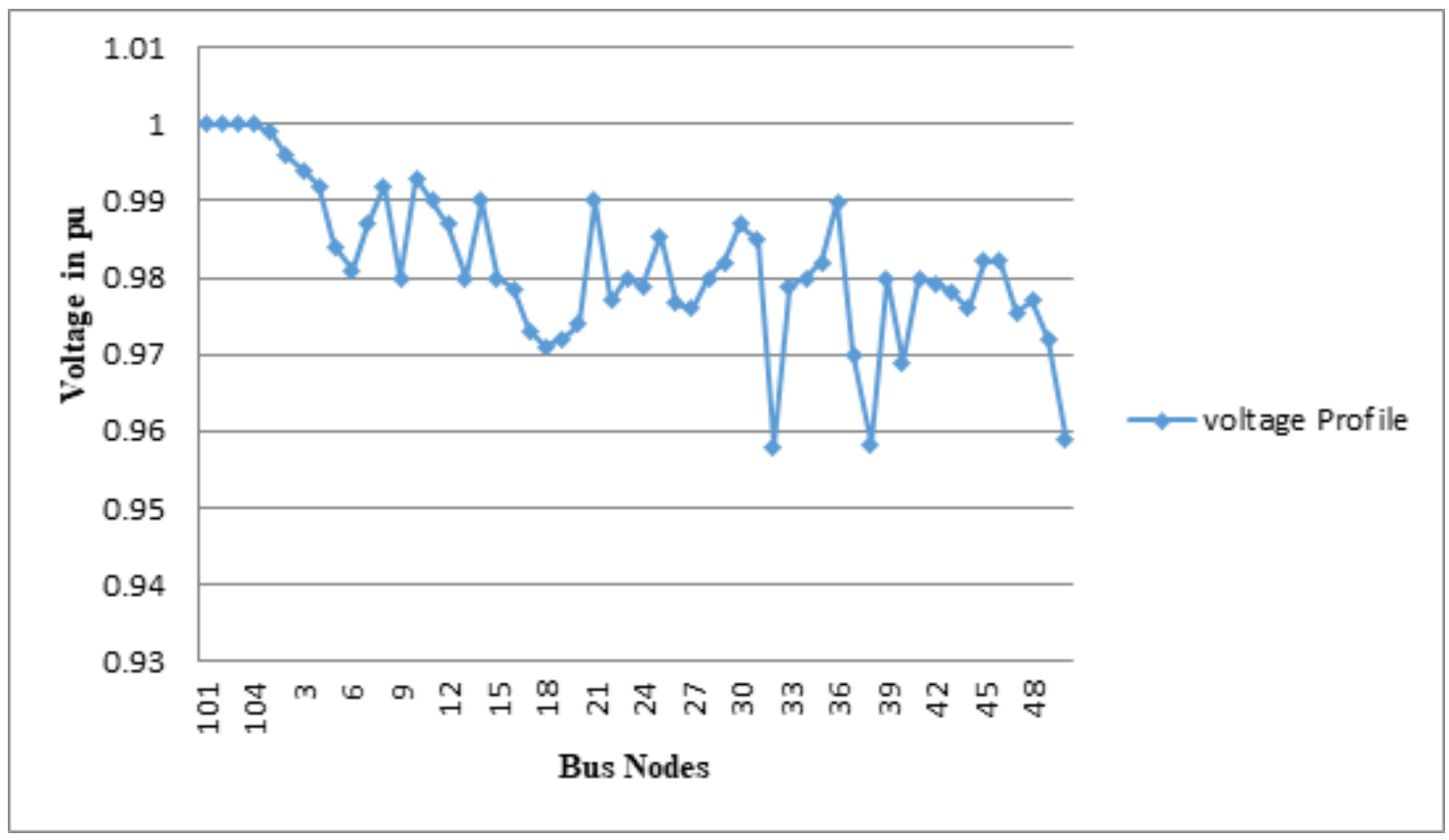

Fig 8. Voltage profile of bus nodes after the network expansion of period 3

distribution network planners for true expansion of MSDSP by considering the investment cost, operational cost and reliability of the system network.

\section{Conclusion}

This study of multistage planning of the distribution system has been formulated by considering the multi objective problems with the consideration of various constraints to achieve the good results for the practical or real power distribution systems. The planning of practical or real system is generally affected by the investment cost, operational cost, reliability of the system and also power quality of the distribution system. The results presented in this study for the multistage distribution system planning facilitates and enables the real distribution system planners for the decision-making on the technical and economic aspects, so that a good quality solution may be obtained for multistage power distribution network. Furthermore, this distinctive formulated model is more adequate to achieve the attributes of the multistage distribution system planning with multi objective problems even with conflicting objectives. However, the economic analysis is not sufficient to enhance the multistage distribution system network efficiency; it also needs intelligent human decision-making and social factors to deal with the issue more practically and real time multistage distribution system planning. In the future, potentials areas should be considered to solve the multistage distribution system planning in a more practical way by considering today's scenario like inclusion of distributed generated sources and/or energy storage sources/devices for further improvement of the distribution system reliability by minimizing the NSEC under contingency conditions.

\section{References}

1) Ganguly S, Sahoo NC, Das D. Recent advances on power distribution system planning: a state-of-the-art survey. Energy Systems. 2013;4:165-193. Available from: https://dx.doi.org/10.1007/s12667-012-0073-x.

2) Tabares A, Franco JF, Lavorato M, Rider MJ. Multistage Long-Term Expansion Planning of Electrical Distribution Systems Considering Multiple Alternatives. IEEE Transactions on Power Systems. 2016;31(3):1900-1914. Available from: https://dx.doi.org/10.1109/tpwrs.2015.2448942.

3) Singh S, Ghose T, Goswami SK. Optimal Feeder Routing Based on the Bacterial Foraging Technique. IEEE Transactions on Power Delivery. 2012;27(1):7078. Available from: https://dx.doi.org/10.1109/tpwrd.2011.2166567.

4) Junior BRP, Mantovani JRS, Cossi AM, Contreras J. Multiobjective multistage distribution system planning using tabu search. IET Generation, Transmission \& Distribution. 2014;8(1):35-45. Available from: https://dx.doi.org/10.1049/iet-gtd.2013.0115.

5) Wang DTC, Ochoa LF, Harrison GP. Modified GA and Data Envelopment Analysis for Multistage Distribution Network Expansion Planning Under Uncertainty. IEEE Transactions on Power Systems. 2011;26(2):897-904. Available from: https://dx.doi.org/10.1109/tpwrs.2010.2057457. 
6) Haffner S, Pereira LFA, Pereira LA, Barreto LS. Multistage Model for Distribution Expansion Planning With Distributed Generation-Part I: Problem Formulation. IEEE Transactions on Power Delivery. 2008;23(2):915-923. Available from: https://dx.doi.org/10.1109/tpwrd.2008.917916.

7) Haffner S, Pereira LFA, Pereira LA, Barreto LS. Multistage Model for Distribution Expansion Planning with Distributed Generation-Part II: Numerical Results. IEEE Transactions on Power Delivery. 2008;23(2):924-929. Available from: https://dx.doi.org/10.1109/tpwrd.2008.917911.

8) El-Zonkoly AM. Multistage expansion planning for distribution networks including unit commitment. IET Generation, Transmission \& Distribution. 2013;7(7):766-778. Available from: https://dx.doi.org/10.1049/iet-gtd.2012.0289.

9) Ganguly S, Sahoo NC, Das D. Mono- and multi-objective planning of electrical distribution networks using particle swarm optimization. Applied Soft Computing. 2011;11(2):2391-2405. Available from: https://dx.doi.org/10.1016/j.asoc.2010.09.002.

10) Sahoo NC, Ganguly S, Das D. Fuzzy-Pareto-dominance driven possibilistic model based planning of electrical distribution systems using multi-objective particle swarm optimization. Expert Systems with Applications. 2012;39(1):881-893. Available from: https://dx.doi.org/10.1016/j.eswa.2011.07.086.

11) Cossi AM, da Silva LGW, Lázaro RAR, Mantovani JRS. Primary power distribution systems planning taking into account reliability, operation and expansion costs. IET Generation, Transmission \& Distribution. 2012;6(3):274-274. Available from: https://dx.doi.org/10.1049/iet-gtd.2010.0666.

12) Ravadanegh SN, Roshanagh RG. On optimal multistage electric power distribution networks expansion planning. International Journal of Electrical Power \& Energy Systems. 2014;54:487-497. Available from: https://dx.doi.org/10.1016/j.ijepes.2013.07.008.

13) Kumar D, Samantaray SR, Kamwa I. Multi-objective design of advanced power distribution networks using restrictedpopulation-based multi-objective seekeroptimisation-algorithm and fuzzy-operator. IET Gener Transm Distrib. 2015;9:487-497. Available from: https://doi.org/10.1016/j.ijepes.2013.07. 008.

14) Kumar D, Samantaray SR. Design of an advanced electric power distribution systems using seeker optimization algorithm. International Journal of Electrical Power \& Energy Systems. 2014;63:196-217. Available from: https://dx.doi.org/10.1016/j.ijepes.2014.05.073.

15) Kumar D, Samantaray SR. Implementation of multi-objective seeker-optimization-algorithm for optimal planning of primary distribution systems including DSTATCOM. International Journal of Electrical Power \& Energy Systems. 2016;77:439-449. Available from: https://dx.doi.org/10.1016/j.ijepes. 2015.11.047.

16) Shivaie M, Ameli MT, Sepasian MS, Weinsier PD, Vahidinasab V. A multistage framework for reliability-based distribution expansion planning considering distributed generations by a self-adaptive global-based harmony search algorithm. Reliability Engineering \& System Safety. 2015;139:68-81. Available from: https://dx.doi.org/10.1016/j.ress.2015.03.001.

17) Santos SF, Fitiwi DZ, Shafie-Khah M, Bizuayehu AW, Cabrita CMP, Catalão JPS. New Multi-Stage and Stochastic Mathematical Model for Maximizing RES Hosting Capacity - Part II: Numerical Results. IEEE Trans Sustain Energy. 2017;8(1):320-330. Available from: https://doi.org/10.1109/TSTE.2016.2584122.

18) Heidari S, Fotuhi-Firuzabad M, Kazemi S. Power Distribution Network Expansion Planning Considering Distribution Automation. IEEE Transactions on Power Systems. 2015;30(3):1261-1269. Available from: https://dx.doi.org/10.1109/tpwrs.2014.2339301.

19) Heidari S, Fotuhi-Firuzabad M, Lehtonen M. Planning to Equip the Power Distribution Networks with Automation System. IEEE Transactions on Power Systems. 2017;32(5):3451-3460. Available from: https://dx.doi.org/10.1109/tpwrs.2017.2650210.

20) Alotaibi MA, Salama MMA. An Incentive-Based Multistage Expansion Planning Model for Smart Distribution Systems. IEEE Transactions on Power Systems. 2018;33(5):5469-5485. Available from: https://dx.doi.org/10.1109/tpwrs.2018.2805322.

21) Zhao L, Huang Y, Dai Q, Yang L, Chen F, Wang L. Multistage active distribution network planning with restricted operation scenario selection. IEEE Access. 2019;22(7). Available from: https://doi.org/10.1109/access.2019.2936936.

22) Home-Ortiz JM, Pourakbari-Kasmaei M, Lehtonen M, Mantovani JRS. Optimal location-allocation of storage devices and renewable-based DG in distribution systems. Electric Power Systems Research. 2019;172:11-21. Available from: https://dx.doi.org/10.1016/j.epsr.2019.02.013.

23) Gholizadeh-Roshanagh R, Zare K. Electric power distribution system expansion planning considering cost elasticity of demand. IET Generation, Transmission \& Distribution. 2019;13(22):5229-5236. Available from: https://dx.doi.org/10.1049/iet-gtd.2018.6740.

24) Medjoudj R, Bediaf H, Aissani D. Power System Reliability: Mathematical Models and Applications. In: and others, editor. System Reliability. InTech. 2017.

25) Ravadanegh SN, Jahanyari N, Amini A, Taghizadeghan N. Smart distribution grid multistage expansion planning under load forecasting uncertainty. IET Generation, Transmission \& Distribution. 2016;10:1136-1144. Available from: https://dx.doi.org/10.1049/iet-gtd.2015.0673.

26) Arefi A, Abeygunawardana A, Ledwich G. A New Risk-Managed Planning of Electric Distribution Network Incorporating Customer Engagement and Temporary Solutions. IEEE Transactions on Sustainable Energy. 2016;7(4):1646-1661. Available from: https://dx.doi.org/10.1109/tste.2016.2573290.

27) Kalambe S, Agnihotri G. Loss minimization techniques used in distribution network: bibliographical survey. Renewable and Sustainable Energy Reviews. 2014;29:184-200. Available from: https://dx.doi.org/10.1016/j.rser.2013.08.075.

28) Singh S, Ghose T. Improved radial load flow method. International Journal of Electrical Power \& Energy Systems. 2013;44(1):721-727. Available from: https://dx.doi.org/10.1016/j.ijepes.2012.08.005.

29) Kaewmamuang K, Siritaratiwat A, Surawanitkun C, Khunkitti P, Chatthaworn R. A novel method for solving multi-stage distribution substation expansion planning. Energy Procedia. 2019;156:371-383. Available from: https://dx.doi.org/10.1016/j.egypro.2018.11.109.

30) M VMV, I RAH, R RAG. Low voltage distribution system planning using diversified demand curves. International Journal of Electrical Power \& Energy Systems. 2014;61:691-700. Available from: https://dx.doi.org/10.1016/j.ijepes.2014.04.019.

31) Samui A, Singh S, Ghose T, Samantaray SR. A Direct Approach to Optimal Feeder Routing for Radial Distribution System. IEEE Transactions on Power Delivery. 2012;27(1):253-260. Available from: https://dx.doi.org/10.1109/tpwrd.2011.2167522.

32) Primary power distribution systems planning taking into account reliability, operation and expansion costs. IET Gener Transm Distrib. 2012;6(3). Available from: https://doi.org/10.1049/iet-gtd.2010.0666.

33) Sahoo NC, Ganguly S, Das D. Multi-objective planning of electrical distribution systems incorporating sectionalizing switches and tie-lines using particle swarm optimization. Swarm and Evolutionary Computation. 2012;3:15-32. Available from: https://dx.doi.org/10.1016/j.swevo.2011.11.002.

34) Teng JH, Lu CN. Feeder Switch Relocation for Customer Interruption Costs Minimization. IEEE Power Engineering Review. 2001;21(11):63-63. Available from: https://dx.doi.org/10.1109/mper.2001.4311188. 